\title{
Investigation of heat transfer in a triple-glazing type window at greek climate conditions
}

Research Article

\author{
Michalis Gr. Vrachopoulos*, Maria K. Koukou, George Filos, Christos Moraitis \\ 1 Central Greece University of Applied Sciences, Mechanical Engineering Department Energy and Environmental Research \\ Laboratory, 34400 Psachna, Evia, Greece
}

Received 12 December 2012; accepted 23 September 2013

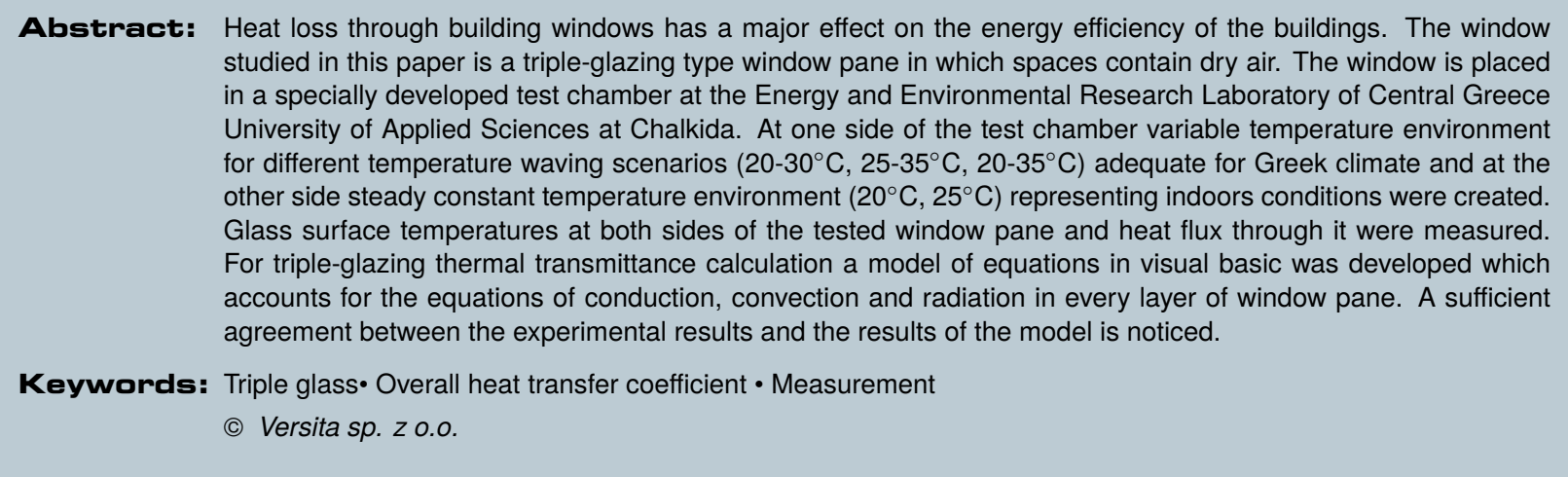

\section{Introduction}

Buildings consume quite a big amount of energy to cover cooling and heating needs. To reduce the energy consumption in buildings it is necessary to reduce heat losses through the building shell. Among the ways to do this is to replace common windows by others with better thermal behavior and lower heat transfer coefficient in order to have efficient reduction of heat losses [1]. The windows are the weak parts of building envelope concerning of the energetic efficiency and the indoor comfort. They are responsible for the solar heat gain

*E-mail: mvrachop@gmail.com inside and for $20-25 \%$ of the heat loss from heated ambient $[2,3]$. During the winter period they contribute to thermal losses through the buildings cell while during the summer period they can lead to overheating indoors. In summer time, it is important to minimize the solar heat gain through windows by shading without reducing the natural illumination, and in the winter time, it is necessary to increase the fraction of solar radiation entering the room without causing any glare.

Window thermal performance is described by the $U$-value, a measure of the heat flux through the window per unit surface area and degree temperature difference between inside and outside. The lower the $U$-value, the better the insulation is. Heat flow through a window is a complex process. Indoors heat is transported outwards through the window construction when it is warmer than outdoors. 
Short-wave solar radiation is transported inwards during daytime. The major part is of course when there is direct solar radiation, but also the diffuse parts give significant contributions. Part of this radiation is "visible" and provides lighting indoors. $U$-value is affected by conductivity, the airflow around the window, and the emissivity of the glass; the lower the conductivity and emissivity of the glass are, the lower the rate of heat loss and the lower the $U$-value are. High-performance window and glazing systems are today available [1-3]: a double or triple glazing, specialized transparent coatings, insulating gas sandwiched between panes, and improved frames concerning of lower heat loss, less air leakage, and warmer window.

The study and construction of more efficient thermal panes requires the analytical numerical and experimental evaluation of heat transfer mechanisms that act through the pane so as to find new technologies and construction materials that will contribute to the significative decrease of heat transfer through them [2]. For the calculation of the overall thermal transmittance various standard regulations have been developed as many researchers have worked to define detailed calculation procedures for determining the thermal and optical transmission properties (e.g., thermal transmittance, total solar energy transmittance) of window systems based on the most up-to-date algorithms and methods, and the relevant solar and thermal properties of all components $[4,5]$.

Researches have been conducted to investigate the heat transfer mechanisms and calculate $U$-value through window glasses [6-12]. Larsson et al. [6] studied the thermal performance of a well-insulated window both numerically and experimentally in a full scale test room and for Sweden climate. The window under consideration was a low-emissive triple-glazing window with two closed spaces filled with the inert gas krypton. An oxidised metal with low emissivity factor coats one pane in each space. Experimental and numerical investigations on the thermal performance of the window were conducted for different winter cases. The numerical predictions agreed well with measurement results and analytical calculations. Robinson et al. [7] used four different techniques to test an advanced, four-pane glazing system and standard doubleglazed unit. The advanced glazing system was found to have a $U$-value of $0.9 \mathrm{~W} / \mathrm{m}^{2} \mathrm{~K}$ and a shading coefficient of 0.48 . Glazing simulation models were used to predict glazing performance. Fang et al. [8] studied the thermal performance of vacuum glazing predicted by using twodimensional (2-D) finite element and three-dimensional (3-D) finite volume models. A guarded hotbox calorimeter was used to determine the thermal performance of vacuum glazing. A method for determining the heat transfer coefficient of the evacuated gap has been established and comparisons are made between the measured and predicted glass surface temperature profiles of the exposed glass area and the heat transfer coefficients of the total glazing system in order to validate the model. Manz et al. [9] investigated heat transfer in triple vacuum glazing by means of (i) an analytical thermal network model and (ii) a numerical finite difference model. The study focused on the impact of the following parameters on thermal transmittance: emittances of glass sheet surfaces inside the cavity, support pillar radius, support pillar separation and thermal conductivity of support pillar material. Fang et al. $[10,11]$ predicted thermal performance of vacuum glazing by using two-dimensional finite element and three-dimensional finite volume models. A guarded hotbox calorimeter was used to determine the experimental thermal performance of vacuum glazing. The experimentally determined overall heat transfer coefficient and temperature profiles along the central line of the vacuum glazing are in very good agreement with the predictions made using both models. Lollini et al. [12] developed a prototype dynamic glazing system and tested. They conducted both experimental work and theoretical analysis aimed at evaluating the possible configurations depending on different weather conditions in several possible places. The analytical models of the buildingplant system were defined by using a dynamic energy simulation software (EnergyPlus). The configuration able to provide the best performances was finally identified by also assessing such performances, integrating the dynamic system in several building types and under different weather conditions.

In this work the performance of a triple-glazing in which spaces contain dry air is studied for various temperatures conditions that exist in Greece especially between April and October. Greece has a Mediterranean climate with plenty of sunshine, mild temperatures and a limited amount of rainfall. However, due to the country's geographical position, its rugged relief and its distribution between the mainland and the sea, there is great variation in it. The triple glazing is placed in a specially developed for that purpose test chamber where at one side variable temperature environment for different temperature waving scenarios $\left(20-30^{\circ}, 25-35^{\circ}\right.$, $20-35^{\circ}$ ) adequate for Greek climate and at the other side steady constant temperature environment $\left(20^{\circ}, 2^{\circ}\right)$ were developed. The work studies the triple glazing performance under these conditions in an integrated way. Air temperature in the chamber was controlled by cooper-constantan thermocouples which transfer data on a daily basis to a computer and with a visual basic code control the electromagnetic vane of four fan coils 
in order to sustain always the desirable air temperature in the chamber. Also, glass surface temperatures at both sides of the tested window pane are measured and registered by cooper-constantan thermocouples and with heat flux sensors daily heat flux through the window pane is measured. Data is registered in a computer and triple glazing thermal transmittance are calculated. For thermal transmittance calculation a model of equations in visual basic has been created which accounts for the equations of conduction, convection and radiation in every layer of window pane.

\section{Experimental approach}

\subsection{Experimental installation}

According to ISO 15099 [4] the triple glazing thermal transmittance can be found by simulating environmental condition involving indoor/outdoor temperature difference - with or without incident solar radiation. The experiments in this work took place in a specially designed test room (Figure 1). The dimensions of the test room are $4 \mathrm{~m} \times 6 \mathrm{~m} \times 4 \mathrm{~m}$, and its roof is covered with roman tiles and a reflective insulation system. The total wall thickness consists of $90 \mathrm{~mm}$ brick, $10 \mathrm{~mm}$ air gap, $1 \mathrm{~mm}$ or $2 \mathrm{~mm}$ reflective insulation, $10 \mathrm{~mm}$ air gap and $90 \mathrm{~mm}$ brick. Reflective insulation is a part of the test room wall construction insulation material of the vertical wall construction in all directions (North, South, East, West). It is also temperature and water proofing element of the roof. The roof, constructed of roman tiles, is based on a wooden support which is protected through the application of reflective insulation and consists of the following layers: joists support of roof, wooden support with thickness $10 \sim 15 \mathrm{~mm}$, cleats of reflective insulation and tiles (wooden or other material e.g. plastic) with thickness $2 \times 10 \mathrm{~mm}$, and roman tile.

The triple glazing studied has been put in the test chamber vertically (Figure 2) so as to create two independent sub-chambers (called hereafter inner side and outer side) where different temperatures and conditions can be developed to evaluate the triple glazing performance. The dimensions of the triple glazing that includes air in the gaps are $2 \mathrm{~m} \times 2 \mathrm{~m}$ and info about its thickness is shown in Table 1. Common aluminum frame without thermal break was used with typical connections (glass/frame) used in the market.

The development of different temperature environment is based on heating and cooling systems using a geothermal heat pump (Figure 3) assuring the provision of hot and cold water which through a distribution and circulation network is stored in tanks. The water through a second

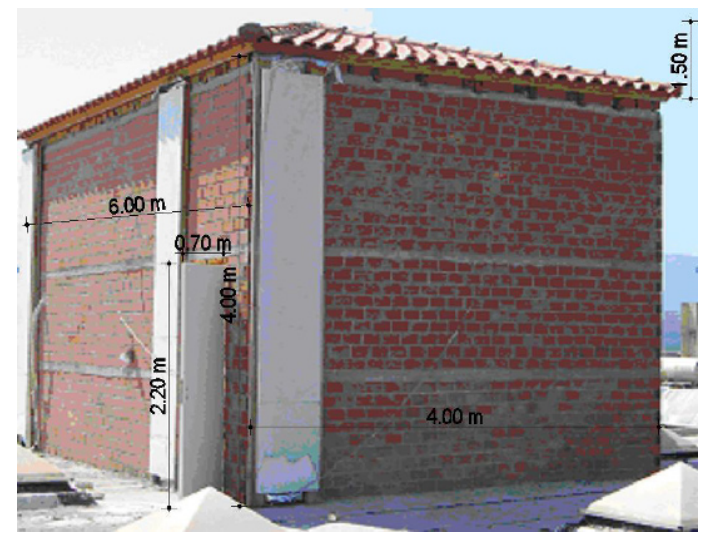

Figure 1. View of the test chamber outside.

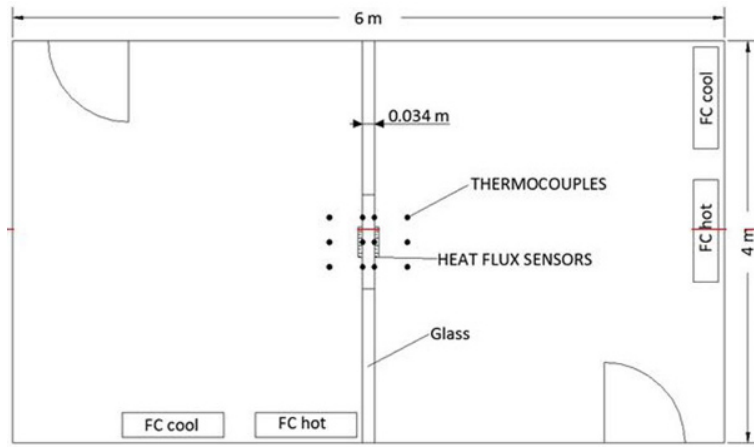

Figure 2. View of the test chamber inside. FC: Fan coils.

distribution network circulates through low temperature heat exchangers (Fan Coils, FC) that have been installed inside the test chamber which by absorbing or rejecting heat develop the inner and outer side temperatures where they have been installed.

Heat provision control in the two parts of the test chamber is achieved through measurement and recording of temperatures. Simultaneously, based on the measured temperatures a series of electro-valves placed in fan coils for heat provision control is controlled. The desired temperatures that will be maintained inside both parts of the test chamber are programmed through the use of a special code that supports the heat provision control at both sides. 
Table 1. Characteristics of the triple glazing studied.

\begin{tabular}{llllll}
\hline $\mathbf{1}^{\text {st }}$ glass & $\mathbf{1}^{\text {st }}$ gap & $2^{\text {nd }}$ glass & $2^{\text {nd }}$ gap & $3^{\text {rd }}$ glass & $\begin{array}{l}\text { Thermal } \\
\text { conductivity }\end{array}$ \\
\hline Thickness $(\mathrm{m})$ & Thickness $(\mathrm{m})$ & Thickness $(\mathrm{m})$ & Thickness $(\mathrm{m})$ & Thickness $(\mathrm{m})$ & $\lambda(\mathrm{W} / \mathrm{mK})$ \\
0.006 & 0.008 & 0.004 & 0.01 & 0.006 & 1 \\
\hline
\end{tabular}

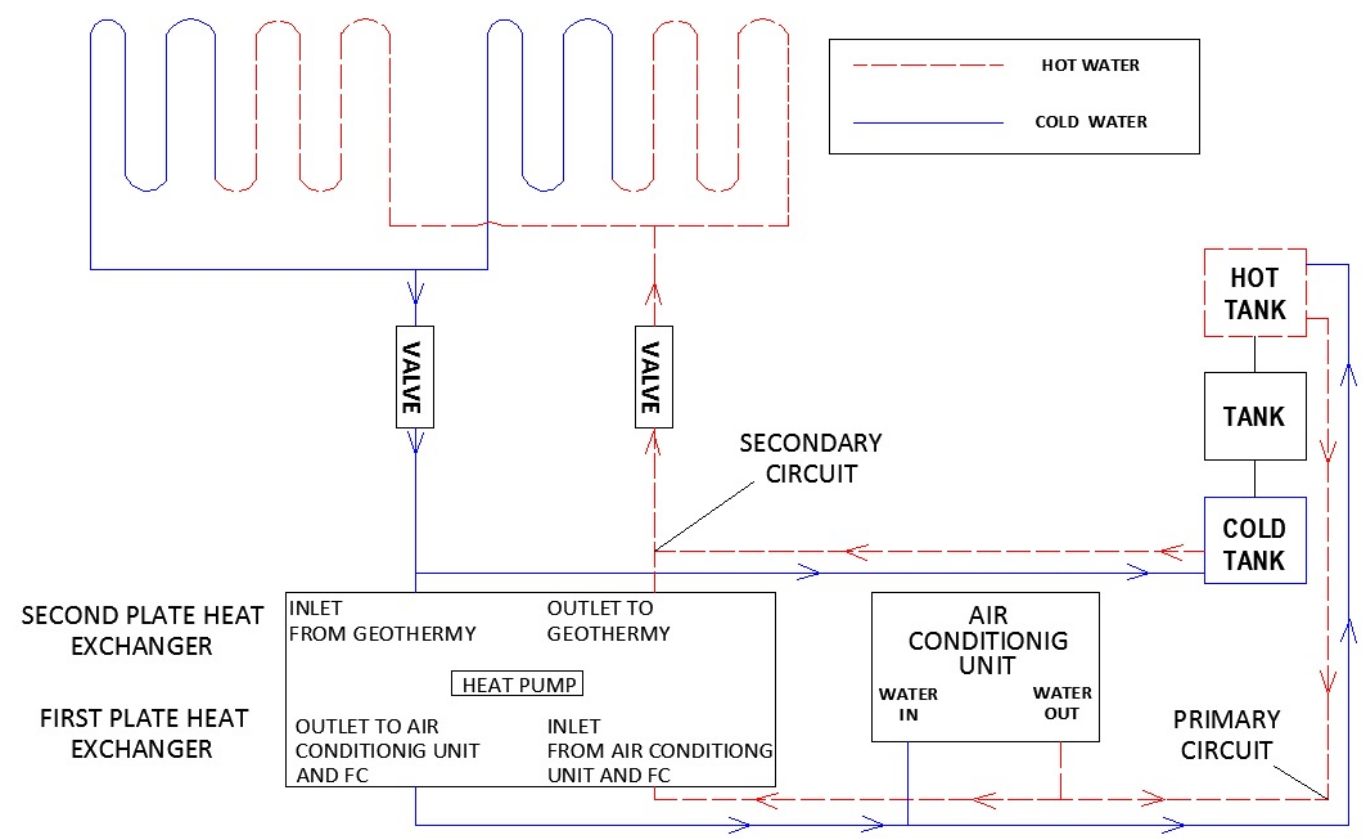

Figure 3. Heat pump network.

\section{Geothermal heat pump}

A geothermal heat pump supports the development of the desired temperature conditions in both sub-chambers (Figure 3). In order to achieve this, a second water tube network (placed at the terrace of the Energy and Environmental Research Lab) is connected with heat pump and consists of three water tanks and four fan coil units. This secondary network provides or eliminates heat focusing on the development of adequate temperature conditions inside both sides of the test chamber.

\section{Fan coils - operation and connection}

Two fan coils have been installed at each side of the test room for heating and cooling purpose (Figure 4a, Figure $4 b$ ). They are connected through plastic tubes with tanks placed outside the test chamber and water is pumped. Fan coils used for cooling are connected in parallel and they are fed from cold water tank while fan coils used for heating are fed from hot water tank.

\section{Sensors operation}

Adam sensors were used to control temperature at both parts of the test room and at the triple glass external surfaces as well. The sensors collect temperature data and control a series of electro-valves used to control heat provision in both sides of the test room. $T$ type thermocouples were used to measure temperature in several points in the chamber. The accuracy of $T$ type thermocouples is described below:

\section{LIMITS OF ERROR}

Standard $1.0^{\circ} \mathrm{C}$ or $0.75 \%$ Above $0^{\circ} \mathrm{C}$

Special $0.5^{\circ} \mathrm{C}$ or 0.4

Six thermocouples are connected to an Adam 4018 to measure temperature at each sub-chamber. Three of them 
(a)

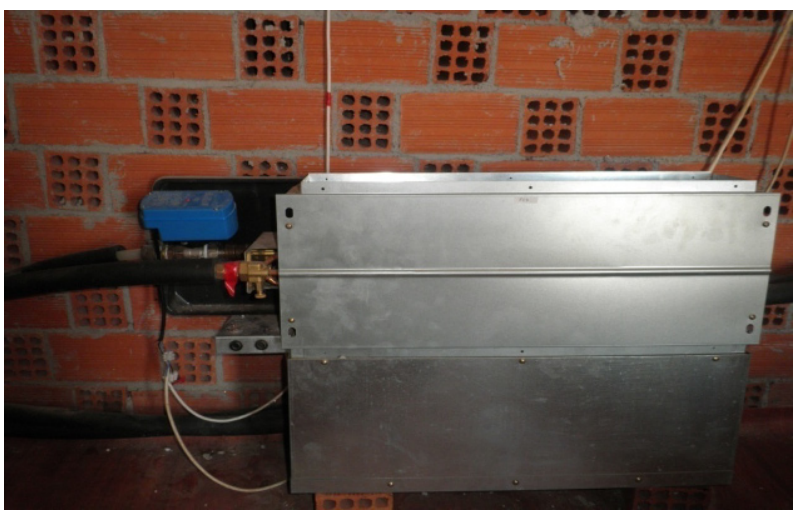

(b)

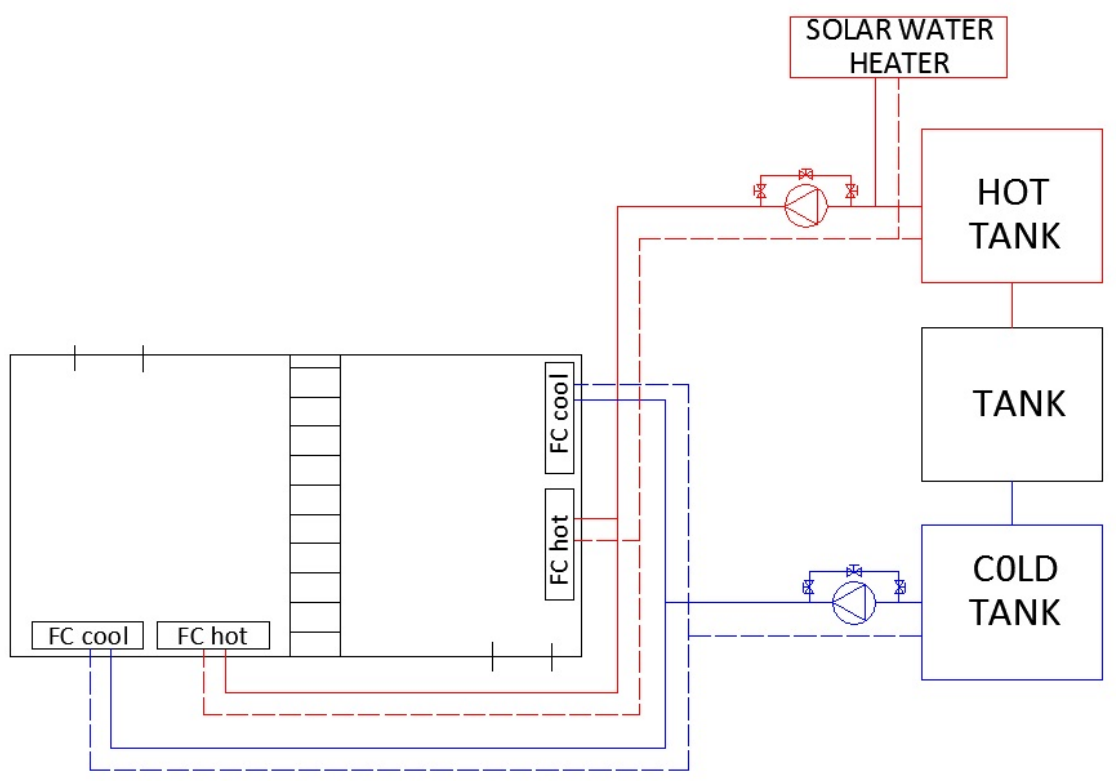

Figure 4. (a) Fan coils; (b) Fan coils connection with tanks.

are located at a distance of $50 \mathrm{~cm}$ from glass external surface and the other three have been put and stuck with special glue at the glass external surface at points 1-3 (Figure 6). Thermocouples that measure at a distance from the glass have been placed inside a box from paper and aluminum (Figure 5) so as to avoid influence from convection and radiation and assure higher accuracy.

An Adam 4025 collects data from the Adam 4018 placed at both sides and transfers them to a personal computer. The software sends commands to an Adam 4060 to manipulate automatically four relay. Each Adam 4060 is connected with an electro valve which is put at the tube of the water inlet of each fan coil. According to the commands that have been inserted in the software the electro-valves open and close and fan coils take or provide heat at each side thus achieving the development of the desired temperatures conditions at both sides.

Heat flow meters (Figure 6) are connected with a data 


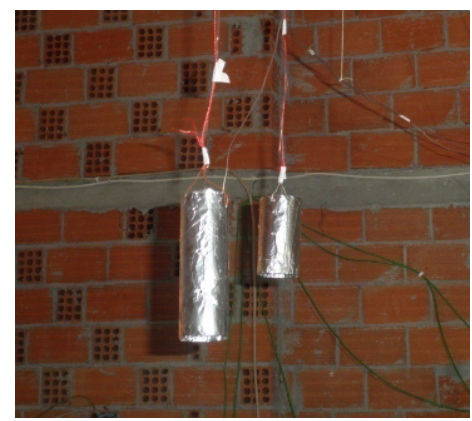

Figure 5. Thermocouples that measure at a distance from the glass.

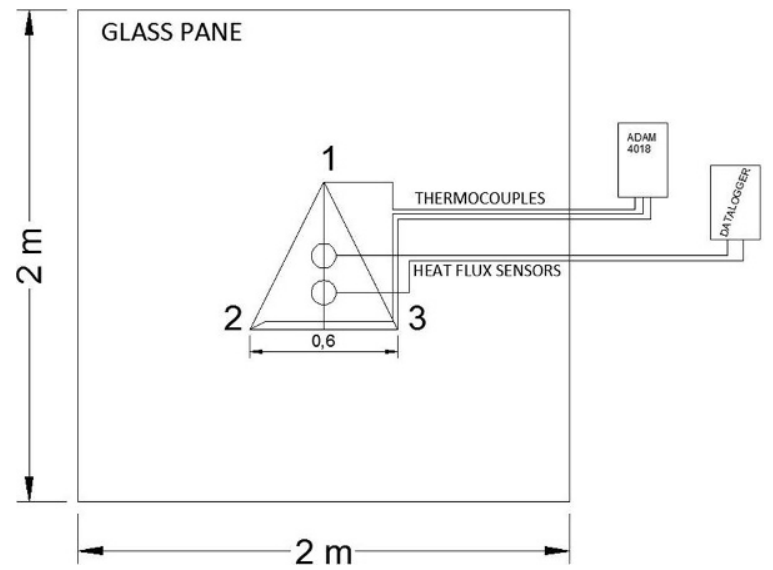

Figure 6. Heat flux measurements points.

logger that collects data through the use of special software. For the measurements HUKSEFLUX HFP01 heat flux sensors were used with expected typical accuracy within $+5 \% /-15 \%$. HFP01 sensors were stuck with special glue at the glass external surface (Figure 6) in order to achieve the highest accuracy. Subsequently measurements were sent to a pc providing the capability to measure with high accuracy heat flow from one side to the other of the chamber through the triple glass glazing.

\subsection{Experimental procedure - Data acquisition}

Experimental procedure included three simulationsscenarios each one lasted seven days: scenario 1: Inner side $20^{\circ}$ Outer side $20^{\circ}-30^{\circ}$, scenario 2: Inner side $25^{\circ}$
Outer side $25^{\circ}-35^{\circ}$, scenario 3 : Inner side $20^{\circ}$ Outer side $20^{\circ}-35^{\circ}$. Measurements were obtained for four control points. The first one is the temperature of outer side of the triple glass pane and the second one is the temperature at the glass external surface at the same side. The third one is the temperature of inner side of the triple glass pane and the fourth one is the temperature at the glass external surface at the same side. Measurements are obtained every 15 minutes for the whole day and for all the days of the simulation. For each day the daily average temperature for each control point is calculated. Finally, after the processing of the collected measurements the overall heat transfer coefficient is calculated.

\section{Theoretical approach}

As temperatures inside the triple glass are not measured for their evaluation and the estimation of triple-glazing glass thermal transmittance the trial and error approach was applied. Each layer was examined separately and as the temperature of the triple glass pane external surfaces $T_{1}, T_{6}$ (Figs. 7a,b) and heat flow were known the temperatures at the inner surfaces $T_{2}, T_{3}, T_{4}, T_{5}$ were calculated together with the heat transfer coefficients for convection $h_{c}$ and radiation $h_{r}$ at the triple glass gaps neglecting convection at the external glass surfaces.

Heat flow through the triple glass is considered steady and one-dimensional. Heat inflow is equal to heat outflow, there is no heat accumulation inside the glass as it is confirmed from recorded measurements thus:

$$
\begin{gathered}
\frac{\dot{Q}}{A}=\frac{\lambda_{\text {glass }}}{b_{\text {glass } 1}}\left(T_{1}-T_{2}\right)=h_{s p 1}\left(T_{2}-T_{1}\right) \\
=\frac{\lambda_{\text {glass }}}{b_{\text {glass } 2}}\left(T_{3}-T_{4}\right)=h_{s p 2}\left(T_{4}-T_{5}\right) \\
=\frac{\lambda_{\text {glass }}}{b_{\text {glass } 3}}\left(T_{5}-T_{6}\right)
\end{gathered}
$$

where $h_{s p}\left(\mathrm{~W} / \mathrm{m}^{2} \mathrm{~K}\right)$ is heat transfer coefficients at triple glass gaps, $b_{\text {glass }}(\mathrm{m})$ are glass widths, $T\left({ }^{\circ} \mathrm{C}\right)$ are temperatures at glass surfaces as depicted in Figure 7 , $\dot{Q}(\mathrm{~W})$ is heat flow perpendicular to $A\left(\mathrm{~m}^{2}\right)$, glass surface. Heat flows through the triple glass by conduction thus according to Fourier's law heat flow density $\dot{q}$ for steady one dimensional condition:

First glass:

$$
[1] \Rightarrow T_{2}=T_{1}-\frac{\dot{q} \cdot b_{\text {glass } 1}}{\lambda_{\text {glass }}}
$$

Second glass:

$$
[1] \Rightarrow T_{4}=T_{3}-\frac{\dot{q} \cdot b_{\text {glass } 2}}{\lambda_{\text {glass }}}
$$


(a)

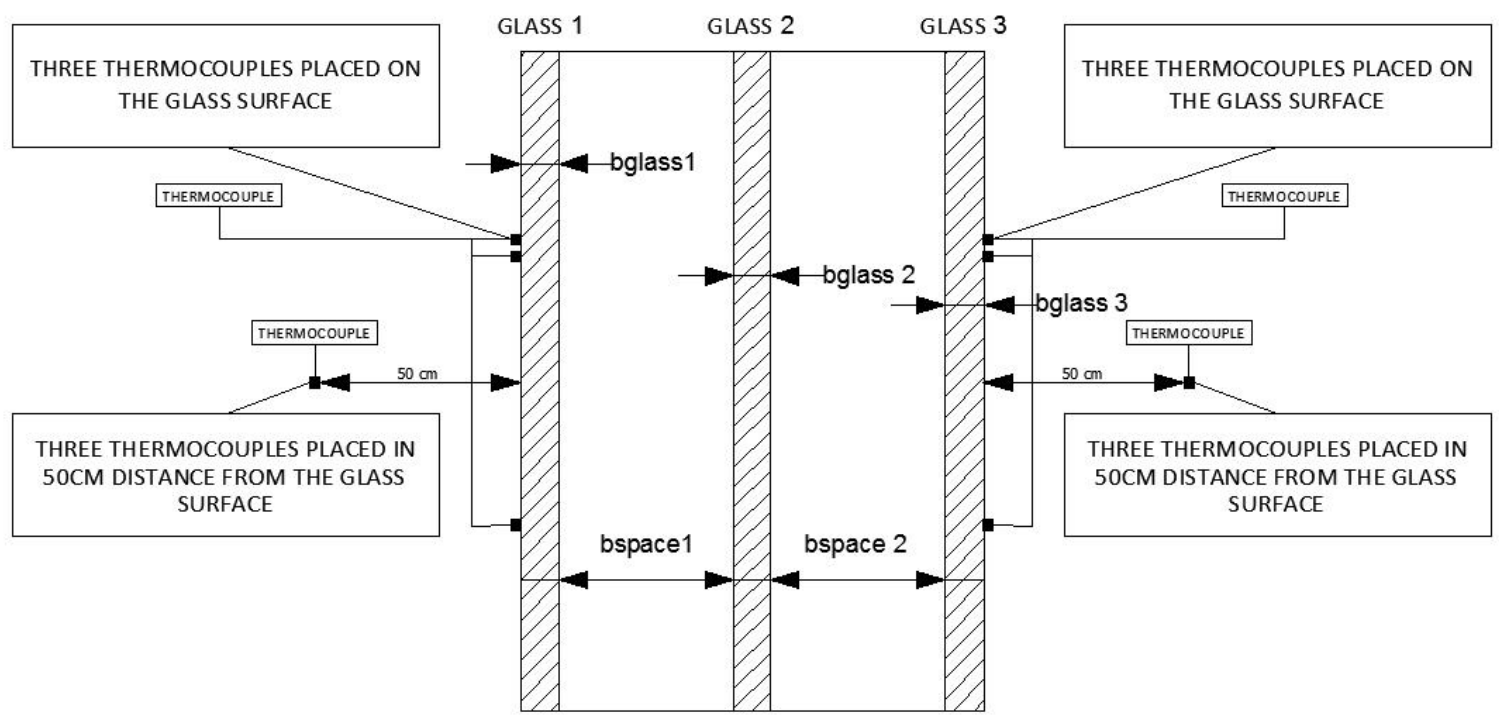

(b)

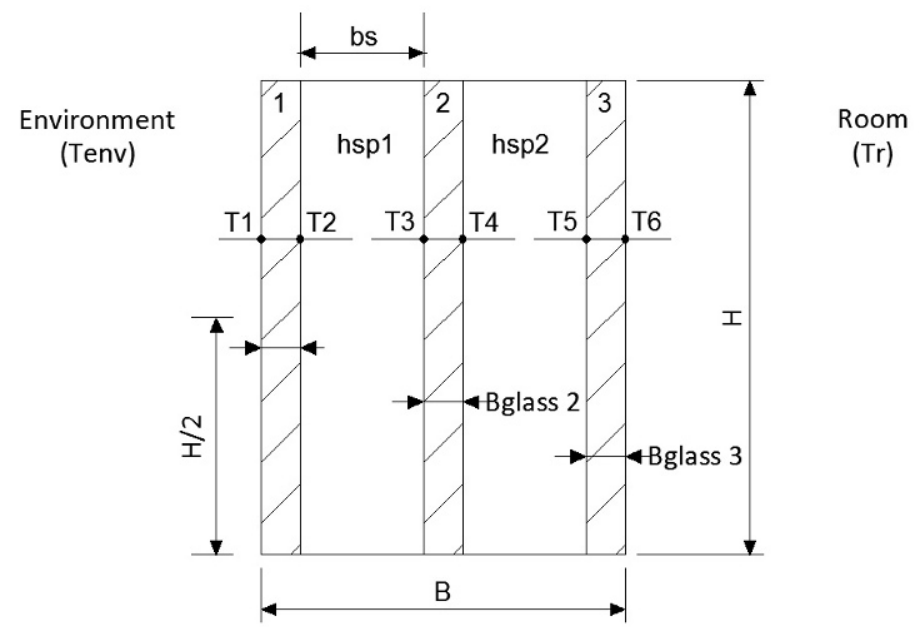

Figure 7. (a), (b) Temperatures at triple glass surfaces.

Third glass:

$$
[1] \Rightarrow T_{6}=T_{5}-\frac{\dot{q} \cdot b_{\text {glass } 3}}{\lambda_{\text {glass }}}
$$

where $\lambda_{\text {glass }}$ is thermal conductivity of glass material $(\mathrm{W} / \mathrm{mK}), b_{\text {glass }}(\mathrm{m})$ is glass thickness, $T_{1}, T_{2}, T_{3}, T_{4}, T_{5}$, $T_{6}\left({ }^{\circ} \mathrm{C}\right)$ are surface temperatures as depicted in Figure $7 \mathrm{~b}$.
Temperature $T_{6}$ is calculated by (4) and it is also measured thus a comparison can be made to justify model validity. Heat transfer through the triple glass gaps takes place through convection [13] and radiation [14]. Heat flow density can be calculated through Newton relationship [13] e.g. for the first gap:

$$
\dot{q}=h_{s p 1}\left(T_{2}-T_{3}\right) \text { where } h_{s p 1}=h_{r}+h_{c}
$$


where $h_{r}$ and $h_{c}$ are heat transfer coefficients $\left(\mathrm{W} / \mathrm{m}^{2} \mathrm{~K}\right)$ by radiation and convection, respectively, $T_{3}$ and $T_{3}\left({ }^{\circ} \mathrm{C}\right)$ at the inner surfaces of the glass gap.

\section{Calculation of $h_{c}$}

Heat transfer coefficient is calculated as a function of Nusselt number, air thermal conductivity $\lambda_{\text {air }}(\mathrm{W} / \mathrm{mK})$ and gap width $b(\mathrm{~m})$. For vertical closed spaces [14]:

$$
h_{c}=N u \frac{\lambda_{\text {air }}}{b_{\text {space }}}
$$

Nusselt number expresses the \% influence of convection on heat transfer through the gap in comparison with the respective percentage of conduction and it is calculated through Rayleigh number. For vertical closed spaces Nusselt number can be calculated through the following relationships and the maximum value is finally used [14]:

$$
\begin{gathered}
N u=\left[N u_{1}, N u_{2}\right]_{\max } \\
N u_{1}=0.0673838 R a^{\frac{1}{3}}, 5 \cdot 10^{3}<R a<10^{6} \\
N u_{1}=0.028154 R a^{0.4134}, 10^{4}<R a<5 \cdot 10^{4} \\
N u_{1}=1+1.7596678 \cdot 10^{-10} R a^{2.2984755}, R a \leq 10^{4} \\
N u_{2}=0.242\left[\frac{R a}{A}\right]^{0.272}
\end{gathered}
$$

where $R a$ is Rayleigh number:

$$
R a=\frac{\rho^{3} \beta g C_{p} b^{3}\left(T_{a}-T_{b}\right)}{\mu \lambda}
$$

$\rho\left(\mathrm{Kg} / \mathrm{m}^{3}\right)$ is fluid density, $\beta\left(\mathrm{K}^{-1}\right)$ is expansion factor, $\mu$ $\left(\mathrm{Ns} / \mathrm{m}^{2}\right)$ is dynamic viscosity, $\lambda(\mathrm{W} / \mathrm{mK})$ is fluid thermal conductivity, $g\left(\mathrm{~m} / \mathrm{sec}^{2}\right)$ is gravity acceleration, $C_{p}(\mathrm{~J} / \mathrm{kgK})$ is fluid specific heat, $b(\mathrm{~m})$ is gap width and $T_{a}, T_{b}\left({ }^{\circ} \mathrm{C}\right)$ are temperature at glass internal surfaces at the gap.

\section{Calculation of $h_{r}$}

For the calculation of heat transfer coefficient by radiation important role play the glass material emissivity, the view factor $F$ and glasses internal surface temperature at the gaps. In heat transfer through a window pane the view factor $F$ is equal to 1 as heat transfer by radiation takes place between two parallel plates at a short distance [13]. In new technology window glasses special coatings are used and placed at the inner surfaces that decrease emissivity to $80 \%$ thus decreasing significantly heat transfer by radiation through the gaps. Heat transfer coefficient by radiation can be calculated by [13]:

$$
h_{r}=\frac{\varepsilon \sigma\left(T_{a}^{4}-T_{b}^{4}\right)}{\left(T_{a}-T_{b}\right)}
$$

where $\varepsilon$ is emissivity of glass material, $\sigma$ is StefanBoltzman constant and $T_{a}, T_{b}\left({ }^{\circ} \mathrm{C}\right)$ are temperatures at inner glass surfaces.

The overall triple-glazing thermal transmittance (ignoring convection resistances at the external surfaces) $U_{g, s}(\mathrm{~W})$ is calculated by adding the conduction, convection and radiation resistances at the various parts of the tripleglazing studied [13]:

$U_{g, s}=\left(\frac{b_{\text {glass } 1}}{\lambda_{\text {glass }}}+\frac{1}{h_{c 1}+h_{r 1}}+\frac{b_{\text {glass } 2}}{\lambda_{\text {glass }}}+\frac{1}{h_{c 2}+h_{r 2}}+\frac{b_{\text {glass } 3}}{\lambda_{\text {glass }}}\right)^{-1}$

The above equations are implemented in a Visual basic code where data input include daily measurements for external surfaces temperatures and heat flow through the triple glazing and technical characteristics of the glass. Results include temperatures for the six temperatures shown in Figure 7b, heat transfer coefficients by convection and radiation in the gaps and overall tripleglazing heat transfer coefficient.

During the application of periodic changing temperature conditions at the external side and constant temperature conditions at the inner side the sum of heat flow values during the period is equal to the sum of temperature at the external side during the same period minus the sum of temperatures at the inner side during the same period multiplied by the overall heat transfer coefficient. On a 24 hour period basis it holds:

$$
\sum_{0}^{24}=U_{g}\left(\sum_{0}^{24} T_{e n v}-\sum_{0}^{24} T_{R}\right)
$$

and the overall triple-glazing thermal transmittance is calculated by:

$$
U_{g}=\frac{\sum_{0}^{24} q}{\left(\sum_{0}^{24} T_{e n v}-\sum_{0}^{24} T_{R}\right)}
$$


This holds in case there are no very intense temperature changes and the heat transfer coefficient by convection that contributes to the overall heat transfer coefficient may be considered constant. If there is no conditions of constant heat transfer coefficient by convection then the above relation may hold but with higher error. As in temperature field values of $\pm 10 \sim 15^{\circ} \mathrm{C}$ the values of heat transfer coefficient close to a vertical surface do not change significantly with a maximum of $\pm 0.5 \%$ deviation in contrast with other factors as air velocity, the above equation is again valid.

\section{Results and Discussion}

In this section, results for the three simulation environments (hereafter called Scenarios) studied and for one typical day for each scenario are presented and discussed.

\subsection{Scenario 1: Inner side $20^{\circ} \mathrm{C}$ Outer side $20^{\circ} \mathrm{C}-30^{\circ} \mathrm{C}$}

At this simulation the temperature at the inner side is retained constant and equal to $20^{\circ} \mathrm{C}$ and the temperature at the outer side of the triple glass changes from $20^{\circ} \mathrm{C}$ to $30^{\circ} \mathrm{C}$. In Figure 8 results for a typical day and for measured temperature at inner side and the desired and measured temperature variation at the outer side of the test chamber is shown thus confirming that the desired temperature variation has been achieved. In Figure 9 the measured temperature at the external triple glazing surfaces at the inner and outer side is shown. Temperature at the outer external glass surface follows external temperature variation. Temperature at the inner external glass surface is quite lower ranging from $20^{\circ}$ to $24^{\circ}$.

In Figure 10 heat flow variation is shown. Average values have been calculated based on the measured heat flow values at the inner and outer sides of the triple glass. The measured values at the inner and outer side differ for each time moment because of the heat storage at the glass material. However, the calculated total heat flow on a daily basis that enters the triple glazing is equal to the heat flow that exits the triple glazing. Heat flow is maximized in the afternoon following the respective outer temperature change.

The periodic change of air temperature at the external side of the triple glass even under conditions of constant air flow causes the development of different air flow conditions at the neighborhood of the glass external surface. This results to the change of the heat transfer coefficient at the external side of the triple glass. Thus during the day $U_{g}$ shows a variation with the temperature difference occurring between the inner and outer sides of the triple glass (Figure 11).

The value of $U_{g}$ especially in panes with multiple gaps shows a variation depending on the developed temperatures both at the interfaces and at the interior. The developed temperature and the temperature difference between the inner and outer side of the glass may change the heat transfer coefficient because of change in the Grashof number. During the day outer temperature increases usually until 15:00 in the afternoon or later and then it decreases. Thus, $U_{g}$ changes with time and the assumption of an average value for $U_{g}$ may be used as a unique number. Its value depends on various parameters included the area studied, season, etc. Similar remarks may be obtained from the other scenarios.

\subsection{Scenario 2: Inner side $25^{\circ} \mathrm{C}$, Outer side $25^{\circ} \mathrm{C}-35^{\circ} \mathrm{C}$}

The temperature at the inner side is retained constant and equal to $25^{\circ} \mathrm{C}$ and the temperature at the outer side of the triple glass changes from $25^{\circ} \mathrm{C}$ to $35^{\circ} \mathrm{C}$. In Figure 13 results for a typical day and for measured temperature at inner side and outer side of the test chamber are shown. The latter agrees with the desired temperature variation except a slight difference between 12:00 and 20:00. However, this does not influence the value of overall heat transfer coefficient. As the temperature difference is lower, heat flow is lower and the overall heat transfer coefficient remains constant. Temperature at the outer external glass surface follows external temperature variation ranging from $26^{\circ} \mathrm{C}$ to $31^{\circ} \mathrm{C}$ (Figure 12 , Figure 13). Temperature at the inner external glass surface is quite lower.

As it is shown in Figure 14 average heat flow values have been calculated based on the measured heat flow values at the inner and outer sides of the triple glass.

\subsection{Scenario 3: Inner side $20^{\circ} \mathrm{C}$ Outer side $20^{\circ} \mathrm{C}-35^{\circ} \mathrm{C}$}

The temperature at the inner side is retained constant and equal to $20^{\circ} \mathrm{C}$ (Figure 16) and the temperature at the outer side of the triple glass changes from $20^{\circ} \mathrm{C}$ to $35^{\circ} \mathrm{C}$. The measured temperature variation at the outer side of the test chamber is in agreement with the desired temperature variation except a difference between 12:00 and 18:00.

Temperature at the outer external glass surface follows external temperature variation ranging from $20^{\circ} \mathrm{C}$ to $30^{\circ} \mathrm{C}$ (Figure 17) while temperature at the inner external glass surface is quite lower. 


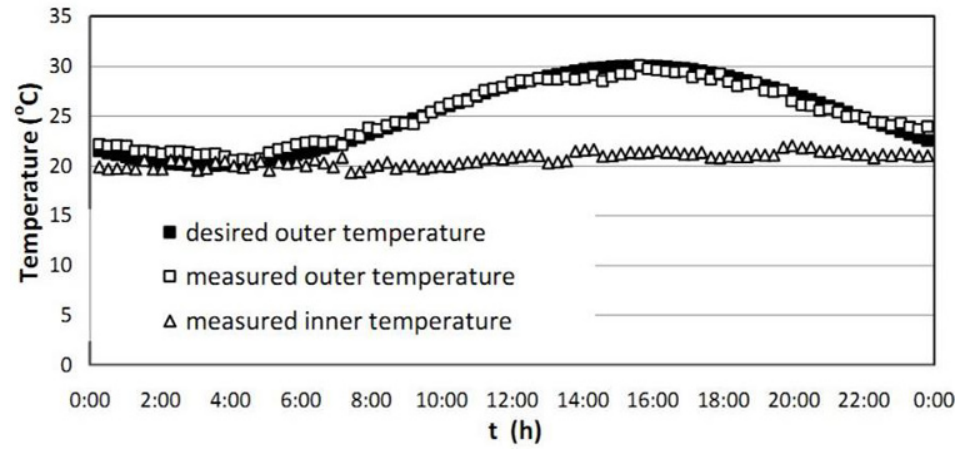

Figure 8. Temperature at the inner and outer side and desired temperature at the outer side. Scenario 1.

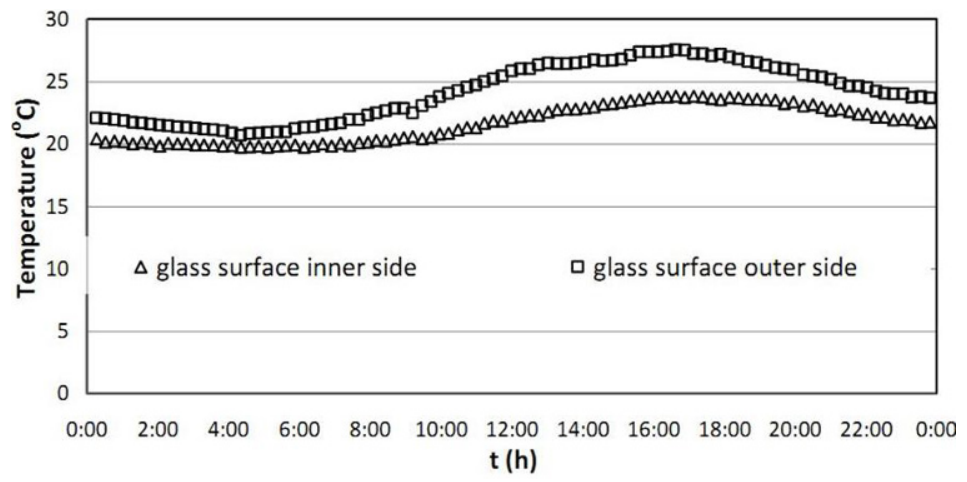

Figure 9. Measured temperature at the external triple glazing surfaces at inner and outer side. Scenario 1.

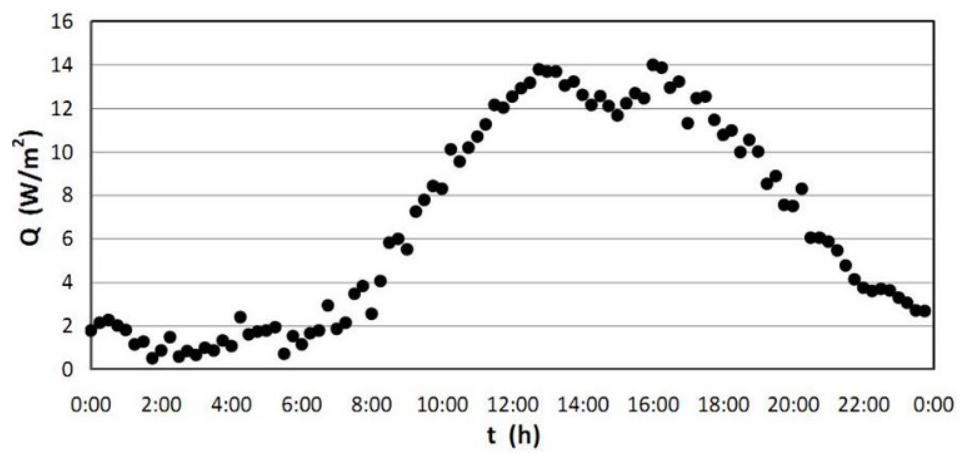

Figure 10. Measured heat flow through the triple glazing. Scenario 1. 


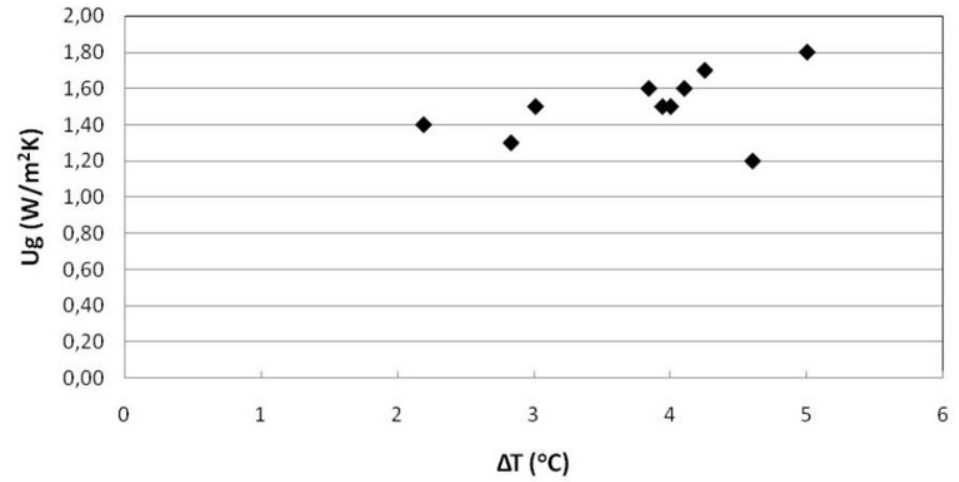

Figure 11. Variation of $U_{g}$ versus temperature difference $\Delta T$. Scenario 1.

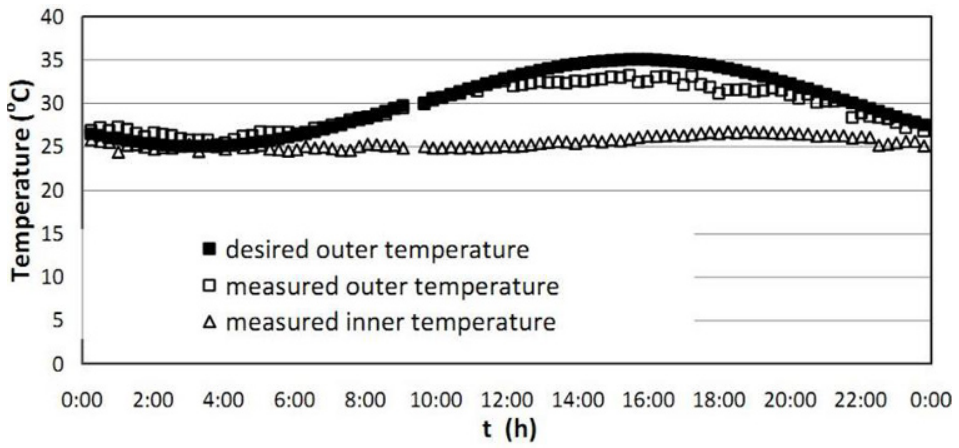

Figure 12. Temperature at the inner and outer side and desired temperature at the outer side. Scenario 2.

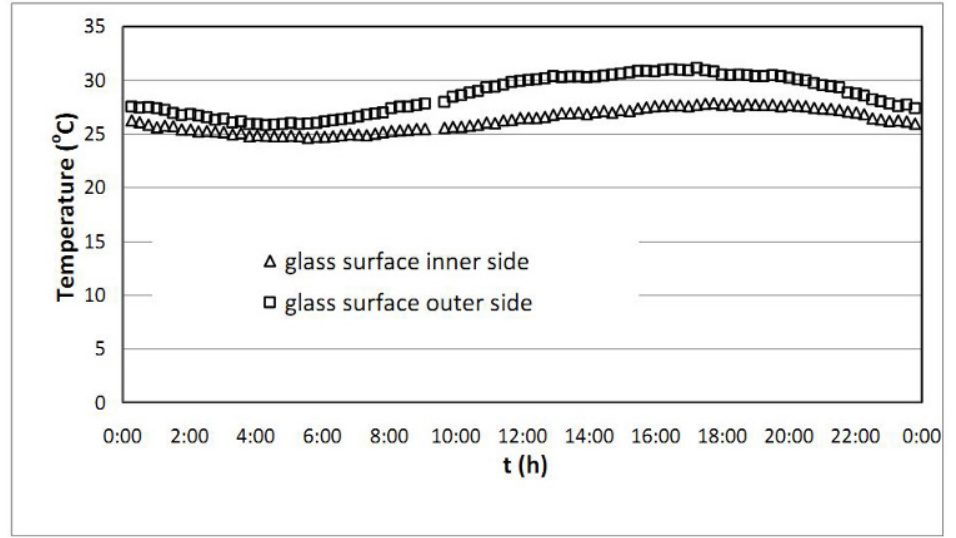

Figure 13. Measured temperature at the external triple glazing surfaces at the inner and outer side. Scenario 2. 


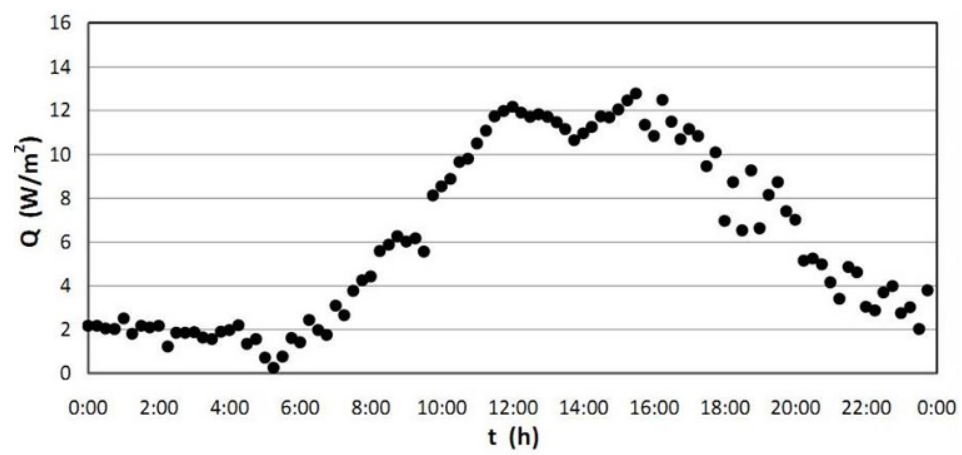

Figure 14. Measured heat flow through the triple glazing. Scenario 2.

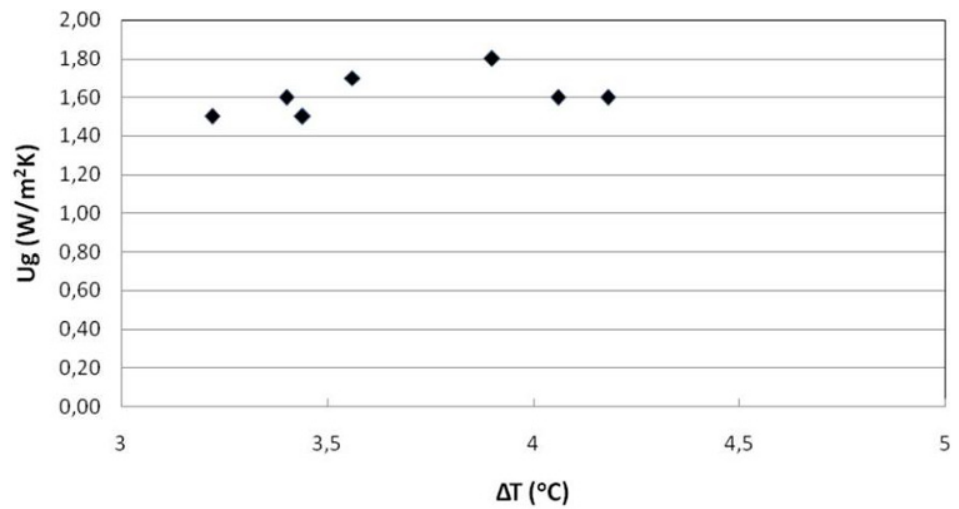

Figure 15. Variation of $U_{g}$ versus temperature difference $\Delta$ Î́d'. Scenario 2.

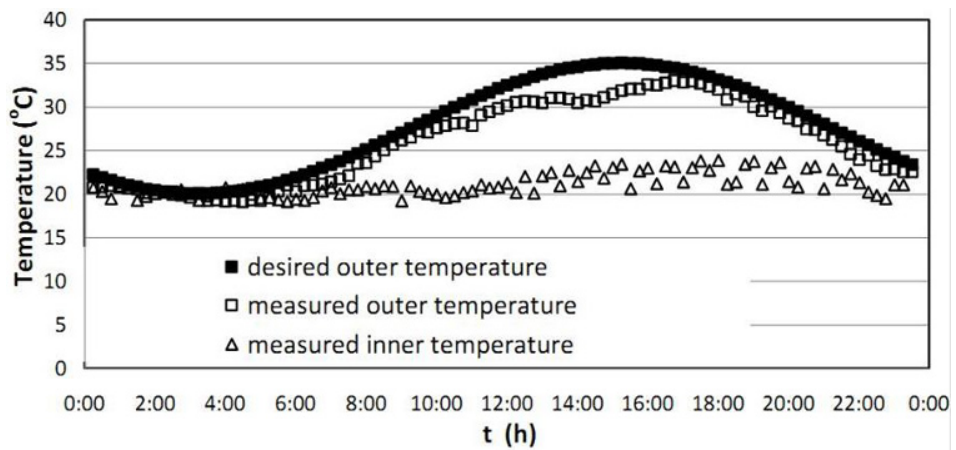

Figure 16. Temperature at the inner and outer side and desired temperature at the outer side. Scenario 3. 


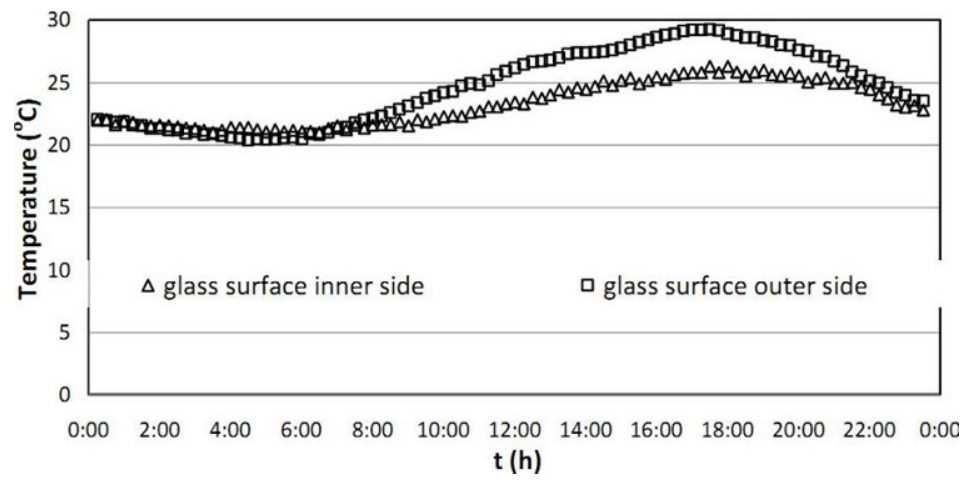

Figure 17. Variation of $U_{g}$ versus temperature difference $\Delta$ Îd'. Scenario 3.

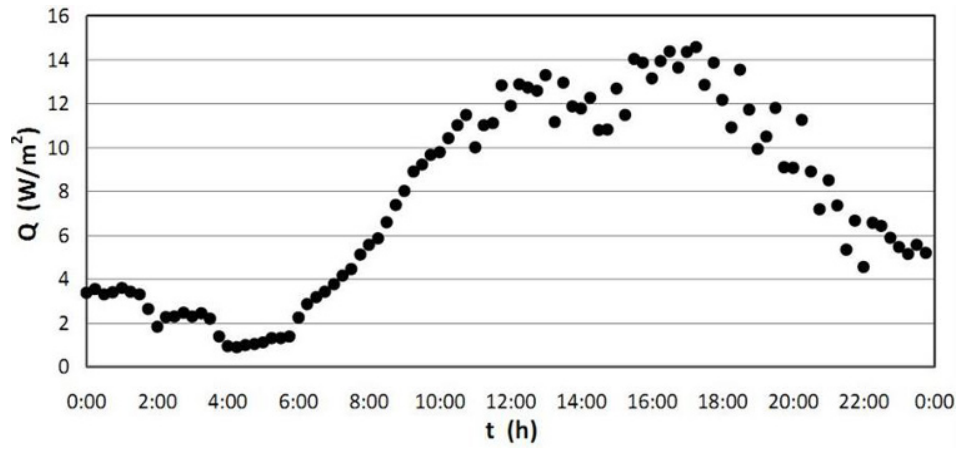

Figure 18. Measured heat flow through the triple glazing. Scenario 3.

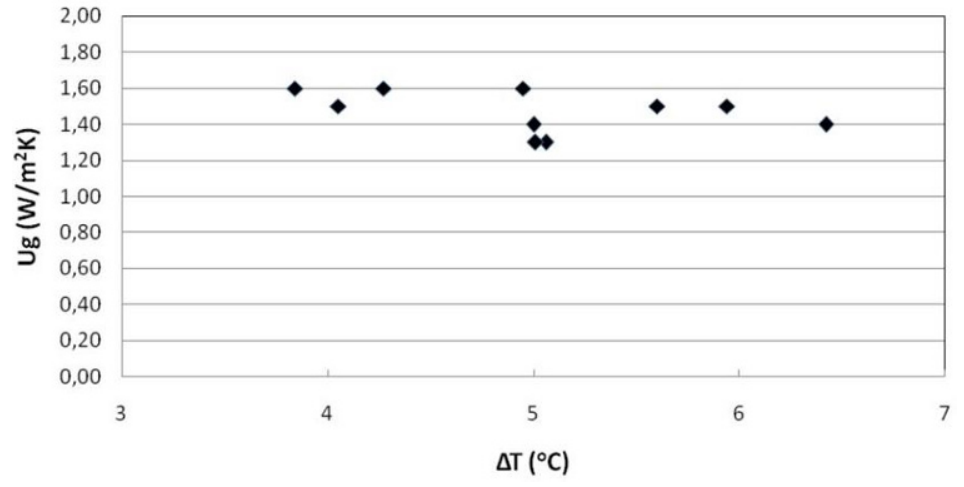

Figure 19. Variation of $U_{g}$ versus temperature difference $\Delta T$. Scenario 3. 
In Figure 18 average heat flow values have been calculated based on the measured heat flow values at the inner and outer sides of the triple glass.

The calculated overall heat transfer coefficient $U_{g}$ in the scenarios of the three typical days shown above is $1.6 \mathrm{~W} / \mathrm{m}^{2} \mathrm{~K}$, however, a variation is noticed during the total duration of each scenario. In the first scenario $U_{g}$ ranges from 1.2-1.8 W/m $\mathrm{m}^{2} \mathrm{~K}$ (Figure 11), in the second scenario it ranges from $1.5-1.8 \mathrm{~W} / \mathrm{m}^{2} \mathrm{~K}$ (Figure 15) and in the third scenario it ranges from $1.3-1.6 \mathrm{~W} / \mathrm{m}^{2} \mathrm{~K}$ (Figure 19).

\section{Conclusions}

The present work focuses on the development of a test room where the thermal behaviour of a triple-glazing pane was studied and its $U_{g}$ value was calculated. A model was developed in visual basic to support experimental procedure where the heat transfer mechanisms that take place in the gaps and in the whole triple glass system were evaluated by examining analytically each triple glass part and solving the respective equations. Experimental plan included three simulation environments each one lasting for seven days. During the day $U_{g}$ shows a variation with the temperature difference occurring between the inner and outer sides of the triple glass caused by the periodic change of air temperature at the external side of the triple glass even under conditions of constant air flow. Important role to the decrease of the glass overall heat transfer coefficient plays the presence of the second air gap as it contributes to the system thermal resistance increase. A sufficient agreement between the experimental results and the results of the model is noticed thus the developed facility can be used for the evaluation of various types of glasses and windows assuming various temperature conditions.

\section{References}

[1] Georgousopoulos G., Heat Transfer coefficient in windows, Aluminium (in Greek) 2006, 138-147

[2] Bülow-Hübe H., Energy-Efficient Window Systems
Effects on Energy Use and Daylight in Buildings, PhD thesis, University Lund Sweden 2001

[3] Simpson J., Thermal performance Kawneer White paper 2001, Aloa Company Editions, UK, 2001, 115

[4] Thermal performance of windows, doors and shading devices - Detailed calculations EN ISO 15099, 2003. EN ISO 15099:2003

[5] Thermal Performance of Windows, Doors, and Shutters - Calculation of Thermal Transmittance. Part 1: Simplified Method. Part 2: Numerical Method for Frames, EN ISO 10077 -1:2000:2002 -2:2004

[6] Larsson U., Moshfegh B., Sandberg M., Thermal analysis of super insulated windows numerical and experimental investigations, Energy and Buildings, 1999, 29, 121-128

[7] Robinson P., Littler J., Thermal Performance Assessment of an Advanced Glazing System, Solar Energy, 1993, 50, No. 2, 129-134

[8] Fang Y., Eames P. C., Norton B., Hyde T. J., Experimental validation of a numerical model for heat transfer in vacuum glazing, Solar Energy, 2006, 80, 564-577

[9] Manz H., Brunner S., Wullschleger L., Triple vacuum glazing: Heat transfer and basic mechanical design constraints, Solar Energy, 2006, 80, 1632-1642

[10] Fang Y., Hyde T. J., Hewitt N., Eames P. C., et al., Comparison of vacuum glazing thermal performance predicted by two and three-dimensional models and experimental validation, Solar Energy Materials and Solar Cells, 2009, 93, 1492-1498

[11] Fang Y., Hyde J. T., Hewitt N., Eames P. C., Theoretical and experimental analysis of the vacuum pressure in a vacuum glazing after extreme thermal cycling, Solar Energy, 2009, 83, 1723-1730

[12] Lollini R., Danza L., Meroni I., Energy efficiency of a dynamic glazing system, Solar Energy, 2010, 84, 526-537

[13] Kakatsios X., Principles of Heat and Mass Transfer, Editions Symeon, Athens, Greece (2006)

[14] Wright J. L., A Correlation to Quantify Convective Heat Transfer Between Vertical Window Glazings, ASHRAE Transactions, 1996, 102, Part 1, 940-946 